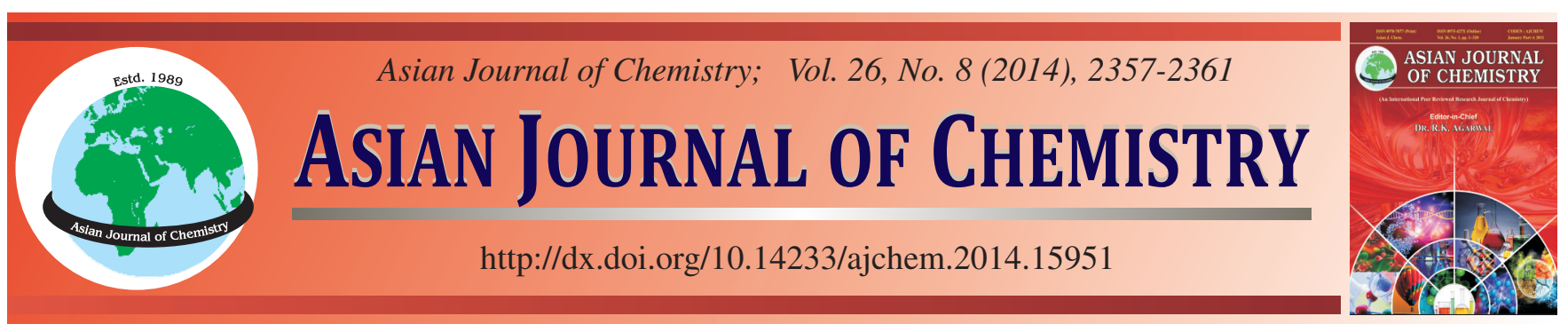

\title{
Theoretical Study on Structures and Properties of High-Energy Density Derivatives of Pyridine
}

\author{
Peng Lian, Wei-Peng Lai ${ }^{*}$, Bo-Zhou Wang, Xi-Jie Wang and Yi-Fen Luo
}

Xi'an Modern Chemistry Research Institute, Xi'an 710065, P.R. China

*Corresponding author: Tel: +86 29 88291050; E-mail: laneph@126.com

\section{INTRODUCTION}

The high-energy-density derivatives of pyridine have become the focus of chemist's attention in recent years because of their high energy, insensitivity and heat-resistant trait ${ }^{1-4} \cdot 2,6-$ Diamino-3,5-dinitropyridine-1-oxide (ANPyO) obtained by Ritter and Licht ${ }^{5}$. It has similar structure with triaminotrinitrobenzene (TATB) melting point over $340^{\circ} \mathrm{C}$, theoretical density of $1.878 \mathrm{~g} \mathrm{~cm}^{-3}$, which makes it one of potential high energy insensitivity explores. 2,4,6-Triamino-3,5-dinitropyridine-1oxide $^{6}$, one derivative of above mentioned compound with the density of $1.876 \mathrm{~g} \mathrm{~cm}^{-3}$, is a potential insensitive high energy explosive. 2,6-Dipicrylamino-3,5-dinitropyridine (PYX) is another well-known pyridine derivative (density is $1.77 \mathrm{~g} \mathrm{~cm}^{-3}$, detonation velocity is $7448 \mathrm{~m} \mathrm{~s}^{-1}$, melting point over $350{ }^{\circ} \mathrm{C}$ ). It is one of the most heat-resistant explosives and has been widely used in the petroleum deep penetrator, explosion exploring of the metagalaxy and nuclear technology etc.

In the theoretical study, Zhao and $\mathrm{Lu}^{7}$ calculated the densities, heats of formation of seven energetic pyridine derivatives and predicted the detonation properties and thermal stabilities. They found that there were good linear relationships between detonation velocity, detonation pressure and the number of nitro group. Türker et al. ${ }^{8}$ calculated the heats of formation for all possible nitro derivatives of pyridine by the application of various density functional theory methods by a proper isodesmic reaction. They suggested that the heat of formation data trends were independent of the selected density functional theory method. Li et al..$^{9}$ calculated the electron structures, molar volumes and thermodynamics properties of 15 polynitropyridine derivatives by the density functional theoretic method. They predicted the crystal structures of 28 polynitropyridine and their oxide and calculated the detonation velocity using stine method. The detonation velocities of 3,5-diamino2,4,6-trinitropyridine and its oxide are 8.2 and $8.6 \mathrm{~km} \mathrm{~s}^{-1}$ respectively. The energies are 15 and $25 \%$ higher than them of triaminotrinitrobenzene.

In the present work, 8 high-energy-density pyridine derivatives were selected whose structures are not reported were designed (Fig. 1). Their IR spectra, thermal stabilities and detonation characters were predicted on the basis of optimized geometries to search for the potential high-energy-density compounds.

\section{CALCULATION}

Density functional theory B3LYP method (Becke's threeparameter hybrid function ${ }^{10}$ with the non-local correlation of Lee et al. ${ }^{11}$ with a $6-31 \mathrm{G}^{* *}$ basis set were carried out for investigating pyridine (1) and eight derivatives (2-9) using Gaussian 09 program $^{12}$. The geometries were fully optimized and the frequency calculations were performed, which indicated that these geometries correspond to be minima (no imaginary frequency) in the potential energy surfaces. The harmonic frequencies and IR spectra were obtained on the basis of vibrational analysis calculations. The Wiberg bond orders were calculated by the analysis of nature bond orbit (NBO). 

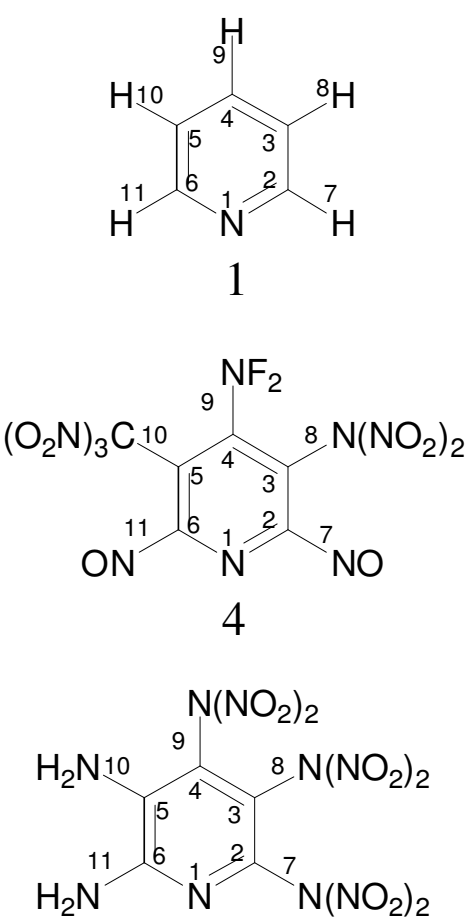

7

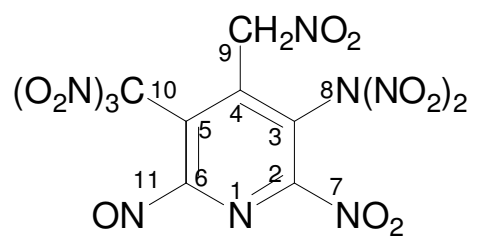

2<smiles>O=[N+]([O-])C1=N[C@H](NF)[C@H]([N+](=O)[O-])[C@H]([N+](=O)[O-])[C@H]1[N+](=O)[O-]</smiles>

5

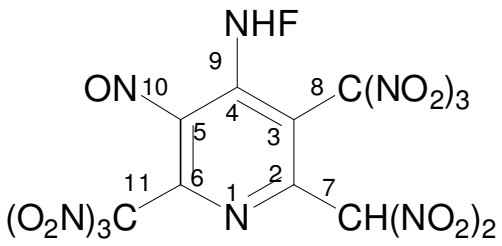

8<smiles>O=Nc1nc([N+](=O)[O-])c([N+](=O)[O-])c([N+](=O)[O-])c1[N+](=O)[O-]</smiles><smiles>O=[N+]([O-])c1c([N+](=O)[O-])c([N+](=O)[O-])c([N+](=O)[O-])c([N+](=O)[O-])c1[N+](=O)[O-]</smiles>

6<smiles>O=[N+]([O-])c1nc(F)c([N+](=O)[O-])c([N+](=O)[O-])c1[N+](=O)[O-]</smiles>

9

Fig. 1. Structures and atomic numbering of pyridine and derivatives

The density and enthalpy of formation play key role during the design and estimate of energetic materials. In the work, the densities of 8 compounds were predicted by equation $\rho=\mathrm{M} / \mathrm{V}_{\mathrm{m}}$. Their molar volumes $\left[\mathrm{V}_{\mathrm{m}}\right]$, which were defined as inside a contour of 0.001 electrons/Bohr ${ }^{3}$ densities, were evaluated using a Monte Carlo integration. Their solid phase enthalpies of formation $\left[\Delta \mathrm{H}_{\mathrm{f}}(\right.$ solid $\left.)\right]$ can be obtained from the gas phase enthalpies of formation using Hess' law of constant heat summation [eqn. (1)]. The gas phase enthalpies of formation $\left[\Delta \mathrm{H}_{\mathrm{f}}(\right.$ gas $\left.)\right]$ can be calculated at B3LYP/6-31G ${ }^{* *}$ level and the enthalpies of sublimation $\left[\Delta \mathrm{H}_{\text {sub }}\right]$ can be calculated by eqns. (2-6), which were presented by Politzer et al. ${ }^{13}$.

$$
\begin{aligned}
& \Delta \mathrm{H}_{\mathrm{f}}(\text { solids, } 298 \mathrm{~K})=\Delta \mathrm{H}_{\mathrm{f}}(\mathrm{gas}, 298 \mathrm{~K})-\Delta \mathrm{H}_{\text {sub }}(298 \mathrm{~K}) \\
& \Delta \mathrm{H}_{\text {sub }}(298 \mathrm{~K}, \mathrm{kcal} / \mathrm{mol})=0.000475 \mathrm{~A}^{2} \\
& +2.1194\left(v \sigma_{\text {tot }}^{2}\right)^{0.5}-2.25 \\
& \sigma_{\mathrm{tot}}^{2}=\sigma_{+}^{2}+\sigma_{-}^{2}=\frac{1}{\mathrm{~m}} \sum_{\mathrm{i}=1}^{\mathrm{m}}\left[\mathrm{V}^{+}\left(\mathrm{r}_{1}\right)-\overline{\mathrm{V}}_{\mathrm{s}}^{+}\right]^{2} \\
& +\frac{1}{\mathrm{n}} \sum_{\mathrm{j}=1}^{\mathrm{n}}\left[\mathrm{V}^{-}\left(\mathrm{r}_{\mathrm{j}}\right)-\overline{\mathrm{V}}_{\mathrm{s}}^{-}\right]^{2} \\
& v=\frac{\sigma_{+}^{2} \sigma_{-}^{2}}{\left[\sigma_{\text {tot }}^{2}\right]^{2}} \\
& \mathrm{~V}_{\mathrm{s}}^{+}=\frac{1}{\mathrm{~m}} \sum_{\mathrm{i}=1}^{\mathrm{m}} \mathrm{V}^{+}\left(\mathrm{r}_{\mathrm{i}}\right) \\
& \mathrm{V}_{\mathrm{s}}^{-}=\frac{1}{\mathrm{n}} \sum_{\mathrm{i}=1}^{\mathrm{n}} \mathrm{V}^{-}\left(\mathrm{r}_{\mathrm{j}}\right)
\end{aligned}
$$

where $\mathrm{A}$ is the molecular surface area on the specified isosurface, $v$ is balance parameter, $\mathrm{V}(\mathrm{r})$ is electrostatic potential, $V(r)$ is the value of $V(r)$ at any point $r_{i}$ on the surface, $V^{+}\left(r_{i}\right)$ and $\mathrm{V}^{-}\left(\mathrm{r}_{\mathrm{j}}\right)$ represent the positive and negative value of $\mathrm{V}(\mathrm{r})$ on the surface, $\overline{\mathrm{V}}_{\mathrm{s}}^{+}$and $\overline{\mathrm{V}}_{\mathrm{s}}^{-}$are their averages, $\sigma_{\text {tot }}^{2}$ is the total variance. In this paper, $\mathrm{A}, \mathrm{V}^{+}\left(\mathrm{r}_{\mathrm{i}}\right)$ and $\mathrm{V}^{-}\left(\mathrm{r}_{\mathrm{j}}\right)$ of 8 compounds were calculated at B3LYP/6-31G ${ }^{\text {** }}$ level.

In this work, the detonation velocities (D), pressures (p) and heats $(\mathrm{Q})$ of 8 compounds were estimated by the formulae (eqns. (7-11) of Kamlet-Jacobs ${ }^{14}$.

$$
\begin{gathered}
\mathrm{D}=1.01\left(\mathrm{~N} \overline{\mathrm{M}}^{1 / 2} \mathrm{Q}^{1 / 2}\right)\left(1+1.30 \rho_{0}\right) \\
\mathrm{p}=1.558 \rho_{0} \mathrm{NM}^{1 / 2} \mathrm{Q}^{1 / 2} \\
\mathrm{~N}=(\mathrm{b}+2 \mathrm{c}+2 \mathrm{~d}) / 4 \mathrm{M} \\
\overline{\mathrm{M}}=(56 \mathrm{~d}+88 \mathrm{c}-8 \mathrm{~b}) /(\mathrm{b}+2 \mathrm{c}+2 \mathrm{~d}) \\
\mathrm{Q}=\frac{28.9 \mathrm{~b}=94.05(\mathrm{c} / 2-\mathrm{b} / 4)+0.239 \Delta_{\mathrm{f}} \mathrm{H}_{\mathrm{m}}}{\mathrm{M}}
\end{gathered}
$$

where $\rho_{0}$ is density $\left(\mathrm{g} \mathrm{cm}^{-3}\right)$ and $\mathrm{M}$ is molecular weight and $\Delta_{\mathrm{f}}$ $\mathrm{H}_{\mathrm{m}}$ is standard molar enthalpy of formation $\left(\mathrm{kJ} \mathrm{mol}^{-1}\right)$, that is $\Delta \mathrm{H}_{\mathrm{f}}$ (solid) in eqn. (1).

\section{RESULTS AND DISCUSSION}

Geometries and nature bond orbits: The B3LYP optimized structure parameters (bond length, bond angle and dihedral angle) are listed in Table-1. It could be seen that the bond length of $\mathrm{C}-\mathrm{C}$ and $\mathrm{C}-\mathrm{N}$ bond in pyridine rings (1-9) are 1.307-1.438 $\AA$, which are between the typical single bond length $(1.46 \AA)$ and typical double bond length $(1.22 \AA)$. It is indicated that the substituents base little effect on the bond 
OPTIMIZED GEOMETRIC PARAMETERS OF PYRIDINE AND DERIVATIVES AT THE B3LYP/6-31G**

\begin{tabular}{|c|c|c|c|c|c|c|c|c|c|}
\hline Geometric parameters & 1 & 2 & 3 & 4 & 5 & 6 & 7 & 8 & 9 \\
\hline $\mathrm{R}^{a}(1,2)$ & $1.339(1.337)^{b}$ & 1.307 & 1.330 & 1.325 & 1.320 & 1.318 & 1.332 & 1.340 & 1.326 \\
\hline $\mathrm{R}(2,3)$ & $1.396(1.402)$ & 1.399 & 1.409 & 1.406 & 1.409 & 1.410 & 1.388 & 1.409 & 1.406 \\
\hline $\mathrm{R}(3,4)$ & $1.394(1.392)$ & 1.419 & 1.420 & 1.405 & 1.411 & 1.406 & 1.420 & 1.410 & 1.418 \\
\hline $\mathrm{R}(4,5)$ & $1.394(1.392)$ & 1.418 & 1.403 & 1.401 & 1.415 & 1.399 & 1.394 & 1.395 & 1.404 \\
\hline $\mathrm{R}(5,6)$ & $1.396(1.402)$ & 1.425 & 1.429 & 1.423 & 1.427 & 1.419 & 1.438 & 1.411 & 1.416 \\
\hline $\mathrm{R}(6,1)$ & $1.339(1.337)$ & 1.324 & 1.317 & 1.321 & 1.330 & 1.337 & 1.327 & 1.319 & 1.315 \\
\hline $\mathrm{R}(2,7)$ & 1.089 & 1.495 & 1.461 & 1.473 & 1.435 & 1.441 & 1.435 & 1.518 & 1.520 \\
\hline $\mathrm{R}(3,8)$ & 1.086 & 1.429 & 1.406 & 1.427 & 1.438 & 1.434 & 1.416 & 1.509 & 1.433 \\
\hline $\mathrm{R}(4,9)$ & 1.086 & 1.513 & 1.418 & 1.455 & 1.390 & 1.505 & 1.426 & 1.439 & 1.522 \\
\hline $\mathrm{R}(5,10)$ & 1.086 & 1.517 & 1.506 & 1.514 & 1.492 & 1.423 & 1.382 & 1.444 & 1.459 \\
\hline $\mathrm{R}(6,11)$ & 1.089 & 1.478 & 1.403 & 1.471 & 1.381 & 1.381 & 1.367 & 1.518 & 1.313 \\
\hline $\mathrm{A}(1,2,3)$ & $123.8(123.8)$ & 123.5 & 123.1 & 121.9 & 123.5 & 123.2 & 123.7 & 121.5 & 123.6 \\
\hline $\mathrm{A}(2,3,4)$ & $118.4(118.3)$ & 118.5 & 116.6 & 117.2 & 117.2 & 117.6 & 117.4 & 116.3 & 119.0 \\
\hline $\mathrm{A}(3,4,5)$ & $118.6(118.4)$ & 118.2 & 119.9 & 121.4 & 119.0 & 119.7 & 120.1 & 121.1 & 116.9 \\
\hline $\mathrm{A}(4,5,6)$ & $118.4(118.3)$ & 116.5 & 116.4 & 114.8 & 115.7 & 117.4 & 116.5 & 117.7 & 117.9 \\
\hline $\mathrm{A}(6,1,2)$ & $117.1(117.4)$ & 119.2 & 119.6 & 120.2 & 118.5 & 119.5 & 119.2 & 122.4 & 117.5 \\
\hline $\mathrm{A}(1,2,7)$ & $116.0(116.3)$ & 114.0 & 110.5 & 111.1 & 113.0 & 113.3 & 116.8 & 111.6 & 115.5 \\
\hline $\mathrm{A}(2,3,8)$ & $120.3(120.3)$ & 123.3 & 121.7 & 124.8 & 126.1 & 127.5 & 118.8 & 129.1 & 112.7 \\
\hline $\mathrm{A}(3,4,9)$ & $120.7(120.8)$ & 115.3 & 120.4 & 122.0 & 119.7 & 121.1 & 116.3 & 117.3 & 120.3 \\
\hline $\mathrm{A}(4,5,10)$ & $121.3(121.4)$ & 125.9 & 125.1 & 123.3 & 123.2 & 118.3 & 125.8 & 114.4 & 117.3 \\
\hline $\mathrm{A}(5,6,11)$ & 120.2 & 128.7 & 117.7 & 126.2 & 118.6 & 125.2 & 118.5 & 124.5 & 119.5 \\
\hline $\mathrm{D}(1,2,3,4)$ & 0.001 & 3.011 & 10.55 & 6.028 & -12.63 & 0.911 & 1.138 & -3.802 & -0.136 \\
\hline $\mathrm{D}(2,3,4,5)$ & -0.001 & 0.443 & -3.308 & -0.171 & 1.429 & -0.842 & -1.146 & 4.504 & -3.208 \\
\hline $\mathrm{D}(3,4,5,6)$ & -0.000 & -3.976 & -7.458 & -7.043 & 13.56 & 0.653 & 0.809 & -1.627 & 4.631 \\
\hline $\mathrm{D}(4,5,6,1)$ & 0.002 & 4.835 & 12.97 & 9.741 & -20.40 & -0.499 & -0.429 & -2.289 & -3.097 \\
\hline $\mathrm{D}(5,6,1,2)$ & -0.001 & -1.644 & -6.509 & -4.529 & 10.36 & 0.545 & 0.390 & 3.125 & -0.281 \\
\hline $\mathrm{D}(6,1,2,3)$ & 0.000 & -2.446 & -5.777 & -3.793 & 6.837 & -0.759 & -0.766 & 0.052 & 1.928 \\
\hline $\mathrm{D}(1,2,3,8)$ & 180.0 & -177.7 & -175.8 & -173.6 & 155.0 & -174.8 & -178.6 & 176.8 & -178.3 \\
\hline $\mathrm{D}(2,3,4,9)$ & 180.0 & -176.8 & 173.9 & -176.4 & 177.0 & 176.5 & 174.9 & -171.5 & 176.3 \\
\hline $\mathrm{D}(3,4,5,10)$ & 180.0 & 174.7 & 168.2 & 173.5 & -171.0 & -178.3 & -178.1 & 174.7 & -167.6 \\
\hline
\end{tabular}

${ }^{a} \mathrm{R}$ is bond length $(\AA), \mathrm{A}$ is bond angles $\left({ }^{\circ}\right)$, D is dihedral angles $\left({ }^{\circ}\right),{ }^{b}$ Values in brackets is experimental values by microwave method ${ }^{15}$.

$\mathbf{1}$ = Pyridine; $\mathbf{2 - 9}=$ Pyridine derivatives (Fig. 1 ).

length and the $\mathrm{C}-\mathrm{C}$ bond adjacent to the substituents are elongated and the $\mathrm{C}-\mathrm{N}$ bond are shortened.

For pyridine (1), the calculated values of bond lengths and bond angles are consistent with the experimental values from the microwave method.

The Wiberg bond orders of pyridine and derivatives are listed in Table-2. Nature bond orbits analysis results indicate that the bond order values of $\mathrm{C}-\mathrm{C}$ and $\mathrm{C}-\mathrm{N}$ bond in pyridine rings are in the range of 1.175-1.442 a.u., which range from the typical single bond order ( 1 a.u.) to typical double bond order (2 a.u.). The second-order perturbational stabilization energies illustrate that there is a strong interaction between the $\pi$ orbit and the adjacent $\pi^{*}$ orbit and the interaction energies range from 41.20 to $130.54 \mathrm{~kJ} \mathrm{~mol}^{-1}$. The lone pairs of electrons of $\mathrm{N}$ atom in pyridine ring act on the $\pi^{*}$ orbits of two adjacent bonds and the energies are in the range of 40.40-51.75 kJ $\mathrm{mol}^{-1}$. The interaction in pyridine ring can improve the stability of pyridine ring.

All bond angles in pyridine rings are approximate to $120^{\circ}$ and the highest variational value is $3.6^{\circ}$, which indicated the effects of substituents to bond angles in rings are little. Dihedral angle data show that the pyridine's plane is distorted by substituent and the most variational value of dihedral angle is $20.4^{\circ}$.
Comparing with the corresponding C-C and C-N single bond, the lengths of bond in the ring are shorter and the bonds are more stable because every bond in the ring are nonlocalized. So the relative intensities of the $\mathrm{C}-\mathrm{C}$ and $\mathrm{C}-\mathrm{N}$ bonds, which connect the substituents and pyridine rings, require attentions. The bond length data show that the lengths of C-C bonds (1.492-1.522 $\AA$ ), which link the substituents and pyridine rings, are shorter than the typical C-C bond length (1.540 $\AA$ ).

Harmonic frequencies and spectra: The calculated infrared spectra (IR) of pyridine and its derivatives are presented in Fig. 2 and the corresponding harmonic frequencies and vibration modes are shown in Table-3.

Bathochromic shifts of the stretching vibration signals from eight pyridine derivatives (2-9) could be observed on the predicted IR spectra as the result of conjugated effect. The vibrational frequency ranges of nitro group $\left(-\mathrm{NO}_{2}\right)$ in compounds 2-9 are wide because of the surroundings of nitro group, inductive effect, steric exclusion and so on. The vibrational frequency ranges of nitroso group (-NO) in compounds 2-9 are narrow $\left(1678-1636 \mathrm{~cm}^{-1}\right)$.

Properties: The predicted densities $(\rho)$, solid-phase enthalpies of formation $\left(\Delta_{\mathrm{f}} \mathrm{H}_{\mathrm{m}}\right)$, detonation velocities (D), detonation pressures $(\mathrm{p})$ and heat $(\mathrm{Q})$ of the eight pyridine 
TABLE-2

CALCULATED WIBERG BOND ORDER (a.u.) OF PYRIDINE AND ITS DERIVATIVES AT THE B3LYP/6-31G**

\begin{tabular}{|c|c|c|c|c|c|c|c|c|c|}
\hline Bonds & 1 & 2 & 3 & 4 & 5 & 6 & 7 & 8 & 9 \\
\hline $\mathrm{B}(1,2)$ & 1.427 & 1.439 & 1.365 & 1.391 & 1.427 & 1.439 & 1.354 & 1.358 & 1.398 \\
\hline B $(2,3)$ & 1.430 & 1.332 & 1.313 & 1.312 & 1.281 & 1.281 & 1.374 & 1.366 & 1.319 \\
\hline B $(3,4)$ & 1.436 & 1.341 & 1.297 & 1.340 & 1.289 & 1.316 & 1.245 & 1.324 & 1.299 \\
\hline $\mathrm{B}(4,5)$ & 1.436 & 1.376 & 1.378 & 1.382 & 1.324 & 1.387 & 1.394 & 1.358 & 1.378 \\
\hline B $(5,6)$ & 1.430 & 1.301 & 1.240 & 1.277 & 1.241 & 1.248 & 1.175 & 1.279 & 1.255 \\
\hline B $(6,1)$ & 1.427 & 1.391 & 1.422 & 1.425 & 1.353 & 1.330 & 1.390 & 1.442 & 1.405 \\
\hline B $(2,7)$ & 0.911 & 0.864 & 1.054 & 1.029 & 0.972 & 0.960 & 0.973 & 0.989 & 0.983 \\
\hline B $(3,8)$ & 0.911 & 0.996 & 1.060 & 0.990 & 1.107 & 1.104 & 1.006 & 1.008 & 1.103 \\
\hline B $(4,9)$ & 0.912 & 1.012 & 1.017 & 0.999 & 1.102 & 1.002 & 1.004 & 1.028 & 0.998 \\
\hline B $(5,10)$ & 0.911 & 1.010 & 1.021 & 1.005 & 1.027 & 1.001 & 1.151 & 1.083 & 1.061 \\
\hline B $(6,11)$ & 0.911 & 1.031 & 1.102 & 1.031 & 1.163 & 1.168 & 1.199 & 0.982 & 0.967 \\
\hline
\end{tabular}

TABLE-3

VIBRATIONAL MODELS AND FREQUENCIES OF PYRIDINE AND ITS DERIVATIVES AT THE B3LYP/6-31G ${ }^{* *}$

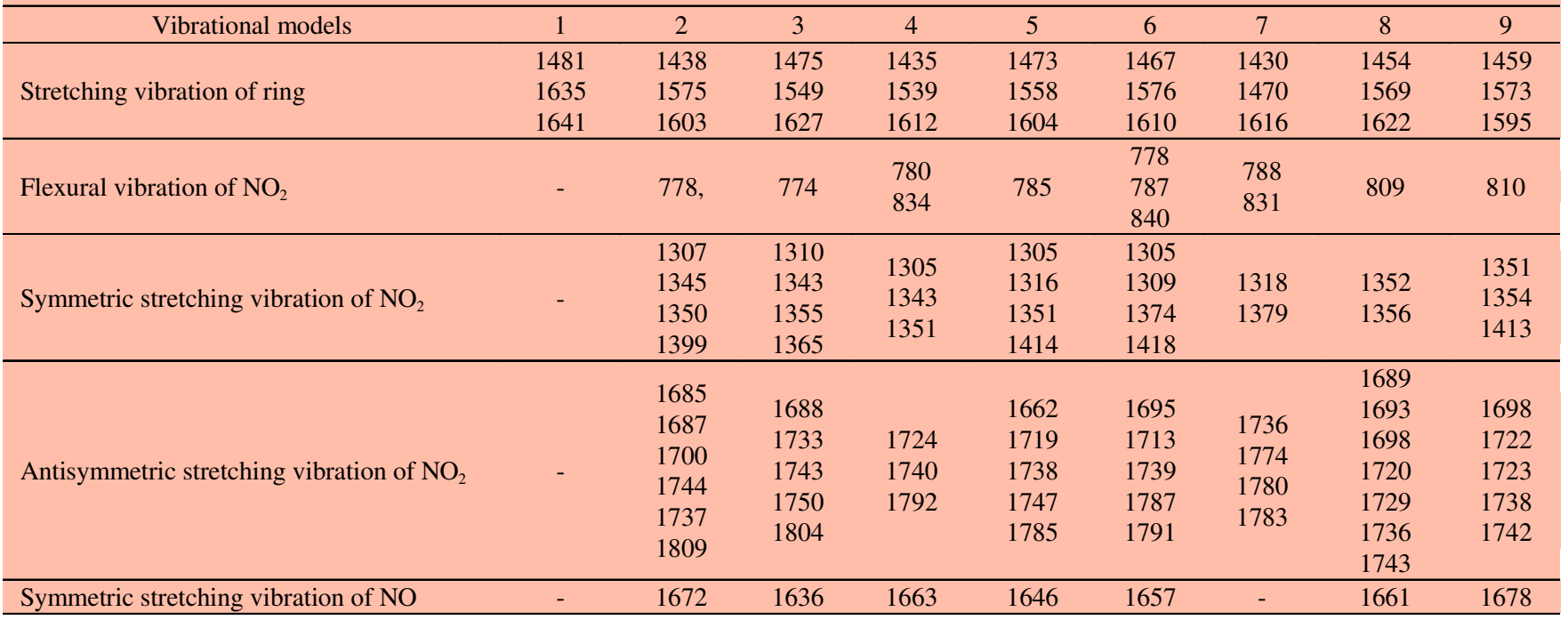

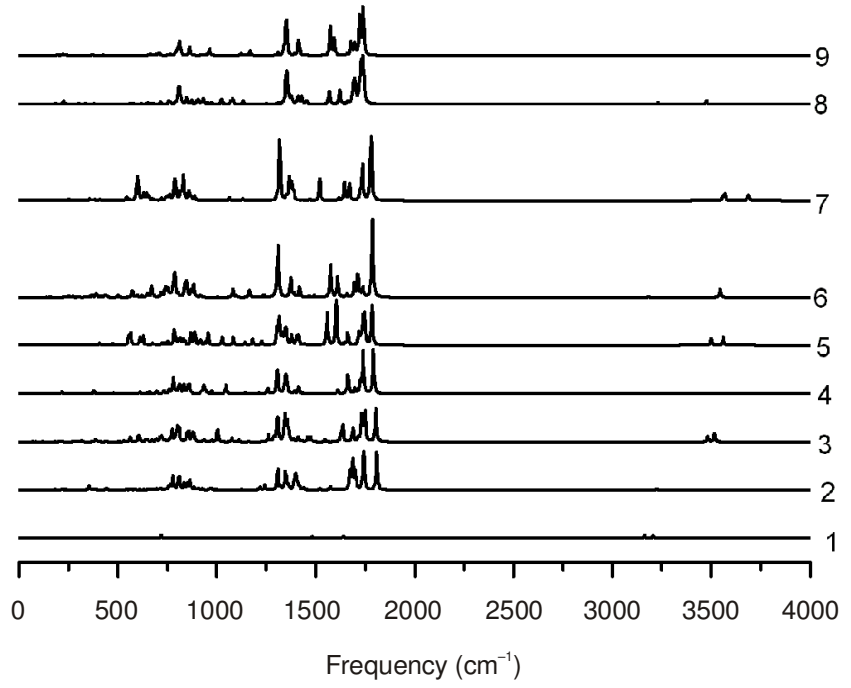

Fig. 2. Calculated IR spectra of pyridine and its derivatives at the B3LYP/ $6-31 G^{* *}$

derivatives are shown in Table-4. The relationship between the predicted densities, detonation velocities, detonation pressures of pyridine derivatives and the numbers of $-\mathrm{NO}_{2}$ or -NO group is presented in Fig. 3.
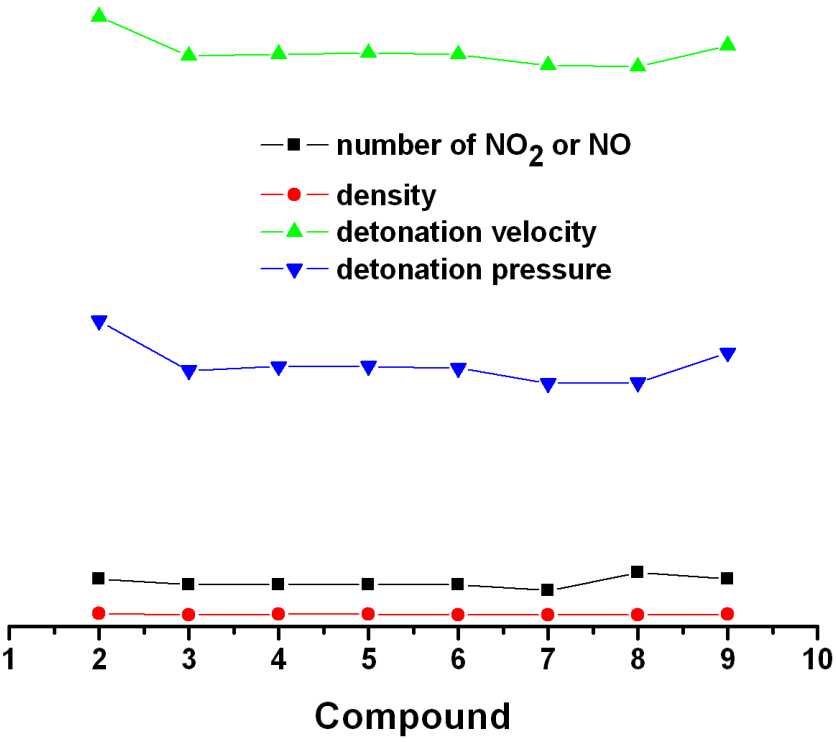

Fig. 3. Relationship between the predicted densities, detonation velocities, detonation pressures of pyridine derivatives and the numbers of $-\mathrm{NO}_{2}$ or $-\mathrm{NO}$ group

As shown in Table-4, the predicted densities of compounds 2-9 are all over $1.9 \mathrm{~g} \mathrm{~cm}^{-3}$ and the predicted detonation velo- 


\section{PREDICTED PROPERTIES OF EIGHT PYRIDINE DERIVATIVES}

\begin{tabular}{cccccc}
\hline Pyridine derivatives & $\rho\left(\mathrm{g} \mathrm{cm}^{-3}\right)$ & $\rho_{\mathrm{f}} \mathrm{H}_{\mathrm{m}}\left(\mathrm{kJ} \mathrm{mol}^{-1}\right)$ & $\mathrm{D}\left(\mathrm{m} \mathrm{s}^{-1}\right)$ & $\mathrm{p}(\mathrm{Gpa})$ & $\mathrm{Q}\left(\mathrm{kJ} \mathrm{kg}^{-1}\right)$ \\
\hline $\mathbf{2}$ & 2.17 & 391.66 & 10181.02 & 51.06 & 7272.33 \\
$\mathbf{3}$ & 2.00 & 400.00 & 9527.95 & 42.79 & 6888.89 \\
$\mathbf{4}$ & 2.03 & 479.20 & 9556.86 & 43.41 & 7032.17 \\
$\mathbf{5}$ & 2.02 & 377.98 & 9579.12 & 43.49 & 6838.38 \\
$\mathbf{6}$ & 2.01 & 390.43 & 9554.72 & 43.15 & 6866.94 \\
$\mathbf{7}$ & 1.93 & 381.69 & 9372.58 & 40.59 & 6682.48 \\
$\mathbf{8}$ & 1.96 & 283.08 & 9348.68 & 40.74 & 7011.33 \\
$\mathbf{9}$ & 2.11 & 221.77 & 9703.13 & 45.70 & 6859.90 \\
\hline
\end{tabular}

cities over $9 \mathrm{~km} \mathrm{~s}^{-1}$, which makes compounds 2-9 high-energydensity compounds. From Fig. 3, the values of density, detonation velocity and detonation pressure of compounds 2-9 are approximatively proportional to the numbers of $-\mathrm{NO}_{2}$ or $-\mathrm{NO}$ group with the exception of compound 8 , which might be a result from the steric exclusion of the substituent $-\mathrm{C}\left(\mathrm{NO}_{2}\right)_{3}$ or $-\mathrm{CH}\left(\mathrm{NO}_{2}\right)_{2}$ and incompact arrangement. Consequently, the density decreasing induces the decreasing of detonation velocity and detonation pressure. It could be concluded that the pyridine ring should connect more $-\mathrm{NO}_{2}$ or $-\mathrm{NO}$ groups and the steric exclusion should be little to design a pyridine derivative with high energy. However, the sensitivity of the compound will increase when the number of the energy group increases, which might bring problems for safety handle.

Stability: In order to further investigate the stabilities of the compounds 2-9, the scan for the potential energy surface was carried out and the transition state and activation energy was obtained. Then the dissociation energies of the easily broken bonds were calculated.

As shown in Table-5, the activation energies of the eight compounds are less than $20 \mathrm{kcal} / \mathrm{mol}$ and the dissociation energies are lower than $120 \mathrm{~kJ} / \mathrm{mol}$, which indicates that the stabilities of all the eight compounds are poor.

\begin{tabular}{|c|c|c|c|}
\hline \multicolumn{4}{|c|}{$\begin{array}{c}\text { TABLE-5 } \\
\text { CALCULATED STABILITIES OF EIGHT } \\
\text { PYRIDINE DERIVATIVES }\end{array}$} \\
\hline $\begin{array}{c}\text { Pyridine } \\
\text { derivatives }\end{array}$ & $\begin{array}{l}\text { Broken } \\
\text { bonds }\end{array}$ & $\begin{array}{c}\text { Activation } \\
\text { energies }(\mathrm{kJ} / \mathrm{mol})\end{array}$ & $\begin{array}{c}\text { Dissociation } \\
\text { energies }(\mathrm{kJ} / \mathrm{mol})\end{array}$ \\
\hline 2 & $\begin{array}{c}\text { 8-N-NO } \\
10-\mathrm{C}-\mathrm{NO}_{2}\end{array}$ & $\begin{array}{l}48.97 \\
57.46\end{array}$ & $\begin{array}{c}102.54 \\
59.87\end{array}$ \\
\hline 3 & $\begin{array}{l}\text { 10-C-NO } \\
\text { 9-N-NO } \\
2\end{array}$ & $\begin{array}{l}44.22 \\
65.40\end{array}$ & $\begin{array}{l}89.40 \\
77.81\end{array}$ \\
\hline 4 & $10-\mathrm{C}-\mathrm{NO}_{2}$ & 36.89 & 81.07 \\
\hline 5 & $10-\mathrm{C}-\mathrm{NO}_{2}$ & 50.75 & 99.86 \\
\hline 6 & $\begin{array}{c}11-\mathrm{N}-\mathrm{F} \\
10-\mathrm{N}-\mathrm{NO}_{2}\end{array}$ & $\begin{array}{l}66.00 \\
68.33\end{array}$ & $\begin{array}{c}195.55 \\
73.90\end{array}$ \\
\hline 7 & $\begin{array}{l}\text { 7-N-NO } \\
\text { 9-N-NO } \\
8-\mathrm{N}_{2} \\
\end{array}$ & $\begin{array}{l}44.64 \\
48.71 \\
50.87\end{array}$ & $\begin{array}{l}75.50 \\
50.34 \\
56.63\end{array}$ \\
\hline 8 & $8-\mathrm{C}-\mathrm{NO}_{2}$ & 44.36 & 71.85 \\
\hline 9 & 9-C-NO & 52.19 & 82.11 \\
\hline
\end{tabular}

\section{Conclusion}

In the present work, density functional theory studies were performed for eight potential pyridine derivatives. The stable geometries of the eight compounds were optimized at B3LYP/ 6-31G** level. The Wiberg bond orders, harmonic frequencies, IR spectra, activation energies and dissociation energies of the broken bond were calculated theoretically. The densities, solid-phase enthalpies of formation and detonation properties were predicted.

The results show that the effects of substituents to the bond length are little. Strong interaction between the $\pi$ orbit and the adjacent $\pi^{*}$ orbit could be observed. On the other hand, the lone pairs of electrons of $\mathrm{N}$ atom in pyridine ring act on the $\pi^{*}$ antibonding orbits of two adjacent bonds and the interaction in pyridine ring can improve the stability of pyridine ring. Bathochromic shifts of the stretching vibration signal from pyridine occur in the eight pyridine derivatives and the vibrational frequency ranges of nitro group are wide because of the surroundings of nitro group, inductive effect, steric exclusion, etc. The result shows eight compounds belong to high-energy-density compounds and their detonation properties are approximatively proportional to the numbers of $-\mathrm{NO}_{2}$ or $-\mathrm{NO}$ group. Unfortunately, the stabilities of the eight compounds are poor.

\section{REFERENCES}

1. K.L. Anderson, L.H. Merwin, W.S. Wilson and J.C. Facelli, J. Mol. Sci., 3, 858 (2002).

2. P.F. Pagoria, G.S. Lee, A.R. Mitchell and R.D. Schmidt, Thermochim. Acta, 384, 187 (2002).

3. J. Wang, J.L. Huang, L.Y. Liao, H.Z. Li, F.D. Nie, L.M. Huang and J.S. Li, Chin. J. Energ. Mater., 16, 480 (2008).

4. J. Cheng, Z.L. Liu, Q.Z. Yao, X.L. Zhou and Y. Du, Chin. J. Explos. Propell., 32, 9 (2009).

5. H. Ritter, H.H. Licht, J. Heterocyclic Chem., 32, 585 (1995).

6. R.A. Hollins, L.M. Merwin, R.A. Nissan, W.S. Wilson and R. Gilardi, Heterocyclic Chem., 33, 895 (1996).

7. G.Z. Zhao and M. Lu, J. Phys. Org. Chem., 26, 211 (2013).

8. L. Türker, S. Gümüs and T. Atalar, J. Energ. Mater., 28, 139 (2010).

9. J.S. Li, Y.G. Huang, H.S. Dong and G.C. Yang, Chin. J. Energ. Mater., 11, 177 (2003).

10. A.D. Becke, J. Chem. Phys., 98, 5648 (1993).

11. C. Lee, W. Yang and R.G. Parr, Phys. Rev. B, 37, 785 (1988).

12. M.J. Frisch et al., Gaussian 09, Gaussian, Inc., Wallingford CT (2009).

13. P. Politzer, J.S. Murray, M.E. Grice, M. Desalvo and E. Miller, Mol. Phys., 91, 923 (1997).

14. M.J. Kamlet and S.J. Jacobs, J. Chem. Phys., 48, 23 (1968).

15. B. Bak, L. Hansen and J.R. Andersen, J. Chem. Phys., 22, 2013 (1954). 